\title{
AN ARCHIMEDEAN RESEARCH THEME: THE CALCULATION OF THE VOLUME OF CYLINDRICAL GROINS
}

\author{
Nicla Palladino \\ Università degli Studi di Salerno \\ Via Ponte don Melillo, 84084 Fisciano (SA), Italy \\ e-mail: nicla.palladino@unina.it
}

\begin{abstract}
Starting from Archimedes' method for calculating the volume of cylindrical wedges, I want to get to describe a method of 18 th century for cilindrical groins thought by Girolamo Settimo and Nicolò di Martino. Several mathematicians studied the measurement of wedges, by applying notions of infinitesimal and integral calculus; in particular I examinated Settimo's Treatise on cylindrical groins, where the author solved several problems by means of integrals.
\end{abstract}

KEY WORDS: Wedge, cylindrical groin, Archimedes' method, G. Settimo.

\section{INTRODUCTION}

"Cylindrical groins" are general cases of cylindrical wedge, where the base of the cylinder can be an ellipse, a parabola or a hyperbole. In the Eighteenth century, several mathematicians studied the measurement of vault and cylindrical groins by means of infinitesimal and integral calculus. Also in the Kingdom of Naples, the study of these surfaces was a topical subject until the Nineteenth century at least because a lot of public buildings were covered with vaults of various kinds: mathematicians tried to give answers to requirements of the civil society who vice versa submitted concrete questions that stimulated the creation of new procedures for extending the theoretical system.

Archimedes studied the calculation of the volume of a cylindrical wedge, a result that reappears as theorem XVII of The Method:

If in a right prism with a parallelogram base a cylinder be inscribed which has its bases in the opposite parallelograms [in fact squares], and its sides [i.e., four generators] on the remaining planes (faces) of the 
prism, and if through the centre of the circle which is the base of the cylinder and (through) one side of the square in the plane opposite to it a plane be drawn, the plane so drawn will cut off from the cylinder a segment which is bounded by two planes, and the surface of the cylinder, one of the two planes being the plane which has been drawn and the other the plane in which the base of the cylinder is, and the surface being that which is between the said planes; and the segment cut off from the cylinder is one sixth part of the whole prism.

The method that Archimedes used for proving his theorem consist of comparing the area or volume of a figure for which he knew the total mass and the location of the centre of mass with the area or volume of another figure he did not know anything about. He divided both figures into infinitely many slices of infinitesimal width, and he balanced each slice of one figure against a corresponding slice of the second figure on a lever.

Using this method, Archimedes was able to solve several problems that would now be treated by integral and infinitesimal calculus.

The Palermitan mathematician Girolamo Settimo got together a part of his studies about the theory of vaults in his Trattato delle unghiette cilindriche (Treatise on cylindrical groins), that he wrote in 1750 about but he never published; here the author discussed and resolved four problems on cylindrical groins.

In his treatise, Settimo gave a significant generalization of the notion of groin and used the actual theory of infinitesimal calculus. Indeed, every one of these problems was concluded with integrals that were reduced to more simple integrals by means of decompositions in partial sums.

\section{HOW ARCHIMEDES CALCULATED THE VOLUMES OF CYLINDRICAL WEDGES}

The calculation of the volume of cylindrical wedge appears as theorem XVII of Archimedes' The Method. It works as follows: starting from a cylinder inscribed within a prism, let us construct a wedge following the statement of Archimedes' theorem and then let us cut the prism with a plane that is perpendicular to the diameter $M N$ (see fig 1.a). The section obtained is the rectangle $B A E F$ (see fig l.b), where $F H^{\prime}$ is the intersection of this new plane with the plane generating the wedge, $H H^{\prime}=h$ is the height of the cylinder and $D C$ is the perpendicular to $H H^{\prime}$ passing through its midpoint. 


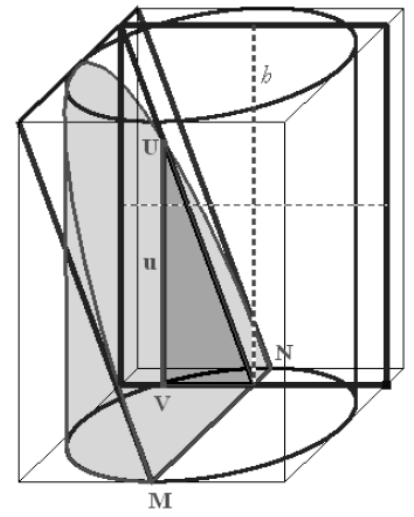

Fig.1.a. Construction of the wedge.

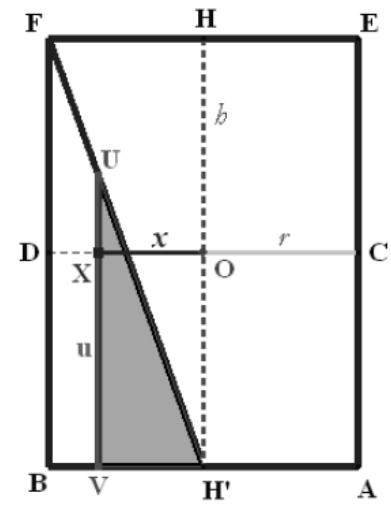

Fig.1.b. Section of the cylinder with a plane perpendicular to the diameter $M N$.

Then let us cut the prism with another plane passing through $D C$ (see fig. 2). The section with the prism is the square $M N Y Z$, while the section with the cylinder is the circle $P R Q R$ '. Besides, $K L$ is the intersection between the two new planes that we constructed.
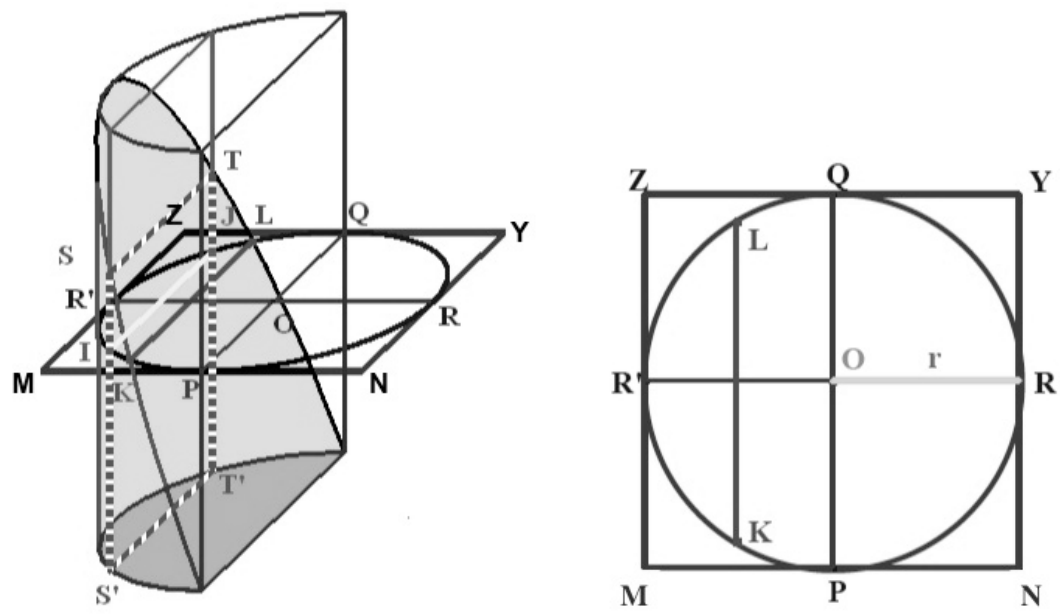

Fig.2. Section of the cylinder with a plane passing through DC.

Let us draw a segment $I J$ parallel to $L K$ and construct a plane through $I J$ and perpendicular to $R R$ '; this plane meets the cylinder in the rectangle 
$S^{\prime} T^{\prime} I^{\prime} T^{\prime}$ and the wedge in the rectangle $S^{\prime} T^{\prime} S T$, as it is possible to see in the figure 3 :

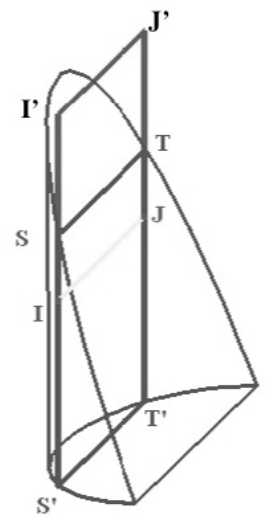

Fig.3. Construction of the wedge.

Because $O H^{\prime}$ and $V U$ are parallel lines cut by the two transversals $D O$ and $H^{\prime} F$, we have

$D O: D X=H^{\prime} B: H^{\prime} V=B F: U V($ see $f i g .4)$
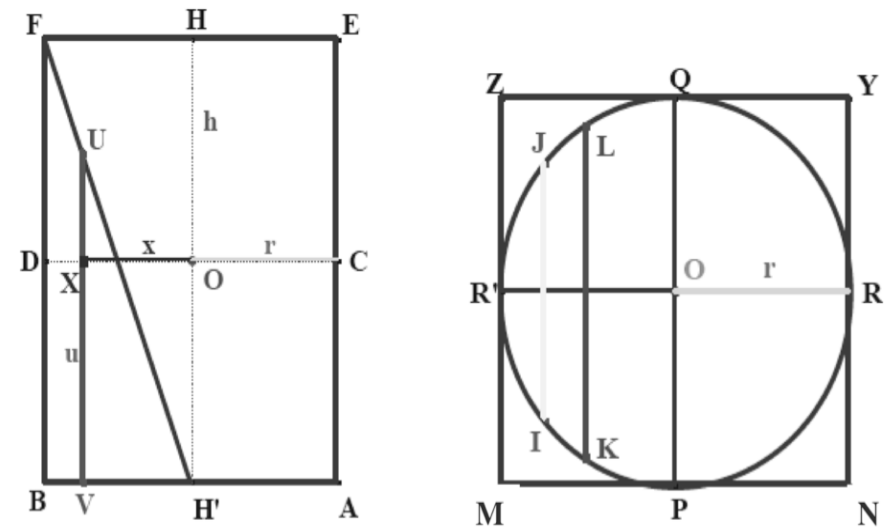

Fig.4. Sections of the wedge

where $B F=h$ and $U V$ is the height, $u$, of the rectangle $S^{\prime} T$ ' $S T$. Therefore $D O: D X=H^{\prime} B: H^{\prime} V=B F: U V=h: u=(h \bullet I J):(u \bullet I J)$. 
Besides $H^{\prime} B=O D$ (that is $r$ ) and $H^{\prime} V=O X$ (that is $x$ ). Therefore

$$
(F B \cdot I J):(U V \cdot I J)=r: x \text {, and }(F B \cdot I J) \cdot x=(U V \cdot I J) \cdot r .
$$

Then Archimedes thinks the segment $C D$ as lever with fulcrum in $O$; he transposes the rectangle $U V \cdot I J$ at the right of the lever with arm $r$ and the rectangle $F B \cdot I J$ at the left with the arm $x$. He says that it is possible to consider another segment parallel to $L K$, instead of $I J$ and the same argument is valid; therefore, the union of any rectangle like $S^{\prime} T^{\prime} S T$ with $\operatorname{arm} r$ builds the wedge and the union of any rectangle like S'T'I'T' with $\operatorname{arm} x$ builds the half-cylinder.

Then Archimedes proceeds with similar arguments in order to proof completely his theorem.

Perhaps it is important to clarify that Archimedes works with right cylinders that have defined height and a circle as the base.

\section{GIROLAMO SETTIMO AND HIS HISTORICAL CONTEST}

Girolamo Settimo was born in Sicily in 1706 and studied in Palermo and in Bologna with Gabriele Manfredi (1681-1761). Niccolò De Martino (1701-1769) was born near Naples and was mathematician, and a diplomat. He was also one of the main exponents of the skilful group of Italian Newtonians, whereas the Newtonianism was diffused in the Kingdom of Naples. Settimo and De Martino met each other in Spain in 1740 and as a consequence of this occasion, when Settimo came back to Palermo, he began an epistolar relationship with Niccolò. Their correspondence collects 62 letters of De Martino and two draft letters of Settimo; its peculiar mathematical subjects concern with methods to integrate fractional functions, resolutions of equations of any degree, method to deduce an equation of one variable from a system of two equations of two unknown quantities, methods to measure surface and volume of vaults ${ }^{1}$.

One of the most important arguments in the correspondence is also the publication of a book of Settimo who asked De Martino to publish in

\footnotetext{
${ }^{1}$ N. Palladino - A.M. Mercurio - F. Palladino, La corrispondenza epistolare Niccolò de Martino-Girolamo Settimo. Con un saggio sull'inedito Trattato delle Unghiette Cilindriche di Settimo, Firenze, Olschki, 2008.
} 
Naples his mathematical work: Treatise on cylindrical groins that would have to contain the treatise Sulla misura delle Volte ("On the measure of vaults"). In order to publish his book, Settimo decided to improve his knowledge of infinitesimal calculus and he needed to consult De Martino about this argument.

In his treatise, Settimo discussed and resolved four problems: calculus of areas, volumes, centre of gravity relative to area, centre of gravity relative to volume of cylindrical groins. The examined manuscript of Settimo, Treatise on cylindrical groins, is now stored at Library of Società Siciliana di Storia Patria in Palermo (Italy), M.ss. Fitalia, and it is included in the volume Miscellanee Matematiche di Geronimo Settimo (M.SS. del sec. $X V I I I)$.

\section{GROINS IN SETTIMO’S TREATRISE}

Settimo's Treatise on cylindrical groins relates four Problems. The author introduces every problem by Definizioni, Corollari, Scolii and Avvertimenti; adding also Scolii, Corollari and Examples after the discussion of it. On the whole, Settimo subdivides his manuscript into 353 articles. The problems to solve are:

Problem 1: to determine the volume of a cylindrical groin;

Problem 2: to determine the area of the lateral surface of a cylindrical groin;

Problem 3: to determine the center of gravity relative to the solidity of a cylindrical groin;

Problem 4: to determine the center of gravity relative to the lateral surface of a cylindrical groin.

Settimo defines cylindrical groins as follows:

"If any cylinder is cut by a plane which intersects both its axis and its base, the part of the cylinder remaining on the base is called a cylindrical groin". 


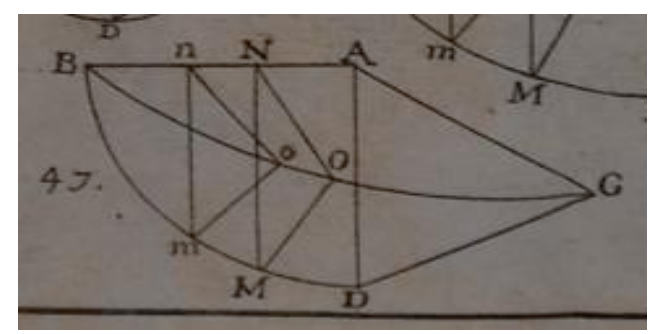

Fig.5. Original picture by De Martino of cylindrical groin (in Elementi della Geometria così piana come solida coll'aggiunta di un breve trattato delle Sezioni Coniche, 1768)

Settimo concludes each one of these problems with integrals that are reduced to more simple integrals by means of decompositions in partial sums, solvable by means of elliptical functions, or elementary functions (polynomials, logarithms, circular arcs).

Settimo and de Martino had consulted also Euler to solve many integrals by means of logarithms and circular arcs ${ }^{2}$.

Let us examine now how Settimo solved his first problem, "How to determine volume of cylindrical groin".

He starts to build a groin as follows: let $A M$ be a generic curve, that has the line $A B$ as its axis of symmetry; on this plane figure he raises a cylinder; then on $A B$ he drew a plane parallel to the axis of the cylinder; this plane is perpendicular to the plane of the basis (see fig. 6).

${ }^{2}$ In particular see L. Euler, Introductio in analysin infinitorum, Lausannae, Apud Marcum-Michaelem Bousquet \& Socios, 1748 and G. Ferraro - F. Palladino, Il calcolo sublime di Eulero e Lagrange esposto col metodo sintetico nel progetto di Nicolò Fergola, Istituto Italiano per gli Studi Filosofici, Napoli, La Città del Sole, 1995. 


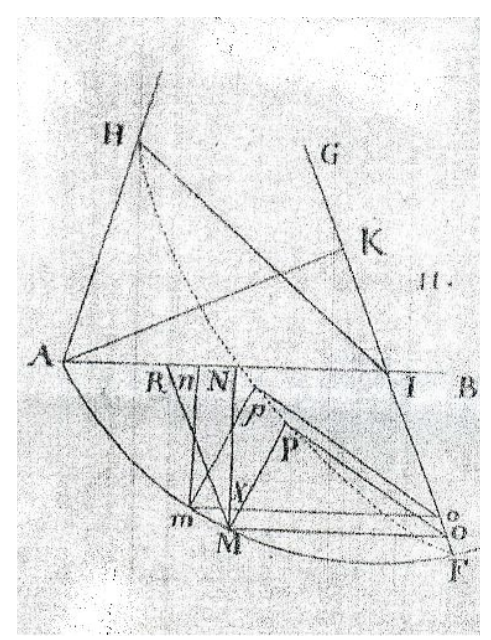

Fig.6. Original picture of groin by Settimo

Let $A H$ be the intersection between this plane and the cylinder; $B A H$ is the angle that indicates obliqueness of the cylinder; the perpendicular line from $H$ to the cylinder's basis falls on the line $A B$.

Let's cut the cylinder through the plane $F H G$, that intersects the plane of basis in the line $F G$. Since we formed the groin $F A G H$, the line $F G$ is the directrix line of our groin. If $F G$ is oblique, or perpendicular, or parallel to $A B$, then the groin $F A G H$ is "obliqua" (oblique), or "diretta" (direct), or "laterale" (lateral). To solve the problem:

1. firstly, Settimo supposes that the directrix $F G$ intersects $A B$ obliquely;

2. then, he supposes that $F G$ intersects $A B$ forming right angles;

3. finally, he supposes that $F G$ is parallel to $A B$.

The directrix $F G$ and the axis $A I$ intersect each other in $I$. On the line $F G$ let's raise the perpendicular line $A K$. Let's put $A I=f, A K=g, K I=h$. From the generic point $M$, let's draw the distance $M N$ on $A B$ and then let's draw the parallel line $M R$ to $F G$. Let us put $A N=x$ e $M N=y$. Then, $N I$ is equal to $f-x$. We have $A K: K I=M N: N R$ and so $N R=\frac{h y}{g}$. Then, let's draw the parallel $M O$ to $A B$ and $M O=R I=f-x+\frac{h y}{g}$.

Let $\mathrm{Mm}$ be an infinitely small arc; let mo be parallel to $A B$ and infinitely near $M O$; mo intersects $M N$ in $X$. On $M O$ let's raise the plane $M P O$ and on 
mo let's raise the plane mpo, both parallel to $A H I$. $M P O$ intersects the groin in the line $P O$ and mpo intersects the groin in the line $p o$.

The prism that these planes form is the "elemento di solidità" (element of solidity) of the groin. Its volume is the area of $M P O$ multiplied by $M X$ (where $M X=d y$ ). So, we are now looking for the area of $M P O$.

Let's put $A H=c$. Since $A H I$ and $M P O$ are similar, we have a proportion: $A I$ is to $A H$ as $M O$ is to $M P$, and $M P=\frac{c}{f}\left(f-x+\frac{h y}{g}\right)$. The planes are parallel, $M P$ is to the perpendicular line on $M O$ from $P$, as radius is to sine of $B A H$. Let $r$ be the radius and let $s$ be the sine.

The dimension of the perpendicular is $M P=\frac{c s}{f r}\left(f-x+\frac{h y}{g}\right)$. Let us multiply it by $M O=f-x+\frac{h y}{g}$ and divide by 2 . Therefore the area of the triangle is $\frac{c s}{2 f r}\left(f-x+\frac{h y}{g}\right)^{2}$. Finally, we found the element of solidity of the groin multiplying by $d y: \frac{c s d y}{2 f r}\left(f-x+\frac{h y}{g}\right)^{2}$.

Since we know the curve of the groin, we can eliminate a variable in our equation $\frac{c s d y}{2 f r}\left(f-x+\frac{h y}{g}\right)^{2}$ and the element becomes "integrable".

Then, Settimo applies the first problem on oblique groins and on the elliptical cylinder

$$
\frac{h y^{2}}{a}=b x-x^{2} \Rightarrow x=\frac{b}{2}+\sqrt{\frac{b^{2}}{4}-\frac{h y^{2}}{a}} .
$$

He writes the differential term like

$$
\frac{c s d y}{2 r f}\left[p^{2}-2 p \sqrt{\frac{b^{2}}{4}-\frac{h y^{2}}{a}}+\frac{b^{2}}{4}+\frac{h y^{2}}{a}+\frac{2 p h y}{g}-\frac{2 h y}{g} \sqrt{\frac{b^{2}}{4}-\frac{h y^{2}}{a}}+\frac{h^{2} y^{2}}{g^{2}}\right]
$$

and says that the problem of searching the volume of the groin is connected with the problem of squaring the ellipse.

At last, he talks about lateral groins, by analogous procedures. 
In the second example, Settimo considers a hyperbolic cylinder and an oblique, direct or lateral groin. He says here that calculating volumes is connected with squaring hyperbolas. In the third example, he considers a parabolic cylinder and an oblique, direct or lateral groin, solving the problems of solidity for curves of equation $y^{m}=x$ that he calls "infinite parabolas".

We note that in the first problem, Settimo is able to solve and calculate each integral, but in the second problem, Settimo shows that its solution is connected with rectification of conic sections. He gives complicated differential forms like sums of more simple differentials that are integrable by elementary functions or connected with rectification of conic sections.

In the "first example" of the "second Problem", the oblique groin is part of an elliptical cylinder, where the equation of the ellipse is known; "the element of solidity" is the differential form:

$$
\frac{c}{f}\left(f-x+\frac{h y}{g}\right) \sqrt{d y^{2}+\frac{s^{2} d x^{2}}{r^{2}}} \Rightarrow \frac{c}{f}\left(p+\sqrt{\frac{b^{2}}{4}-\frac{b y^{2}}{a}}+\frac{h y}{g}\right) \frac{d y \sqrt{\frac{a^{2}}{4}-\frac{a y^{2}}{b}+\frac{s^{2}}{r^{2}} y^{2}}}{\sqrt{\frac{a^{2}}{4}-\frac{a y^{2}}{b}}}
$$

that is decomposition of three differentials:

$$
\frac{c p}{f} \frac{d y \sqrt{\frac{a^{2}}{4}-\frac{a y^{2}}{b}+\frac{s^{2}}{r^{2}} y^{2}}}{\sqrt{\frac{a^{2}}{4}-\frac{a y^{2}}{b}}}+\frac{b c}{a f} d y \sqrt{\frac{a^{2}}{4}-\frac{a y^{2}}{b}+\frac{s^{2}}{r^{2}} y^{2}}+\frac{c h y d y}{f g} \frac{\sqrt{\frac{a^{2}}{4}-\frac{a y^{2}}{b}+\frac{s^{2}}{r^{2}} y^{2}}}{\sqrt{\frac{a^{2}}{4}-\frac{a y^{2}}{b}}}
$$

Settimo starts studying the second differential: when he supposes the inequality $\frac{s^{2}}{r^{2}}<\frac{a}{b}$, he makes some positions and then makes a transformation on the differential that he rewrites like

$$
\frac{b c m}{a f r} \frac{\frac{1}{2} q^{5} d u-\frac{1}{2} q^{3} u^{2} d u}{\left(q^{2}+u^{2}\right)^{2}}+\frac{b c m}{a f r} \frac{\frac{1}{2} q^{5} d u+\frac{1}{2} q^{3} u^{2} d u}{\left(q^{2}+u^{2}\right)^{2}} .
$$


Settimo "constructs the solution", according to the classical method; i.e. he graphically resolves the arc that denotes the logarithm of imaginary numbers and shows that this solution solves the problem to search the original integral.

He calculates the integral of the first addend and transforms the second addend, but here he makes an important observation:

"[this formula] includes logarithms of imaginary numbers [...]; now, since logarithms of imaginary numbers are circular arcs, in this case, from a circular arc the integral of the second part repeats itself. This arc, by 'il metodo datoci dal Cotes' [i. e. Cotes' method] has $q$ as radius and $u$ as tangent".

Roger Cotes' method is in Harmonia Mensurarum ${ }^{3}$; there are also 18 tables of integrals; these tables let to get the "fluens" of a "fluxion" (i.e., the integral of a differential form) in terms of quantities, which are sides of a right triangle. Roger Cotes spent a good part of his youth (from 1709 to 1713) drafting the second edition of Newton's Principia. He died before his time, leaving incomplete and important researches that Robert Smith (1689-1768), cousin of Cotes, published in Harmonia Mensurarum, in 1722, at Cambridge.

In the first part of Harmonia Mensurarum, the Logometria, Cotes shows that problems that became problems on squaring hyperbolas and ellipses, can be solved by measures of ratios and angles; these problems can be solved more rapidly by using logarithms, sines and tangents. The "Scolio Generale", that closes the Logometria, contains a lot of elegant solutions for problems by logarithms and trigonometric functions, such as calculus of measure of lengths of geometrical or mechanical curves, volumes of surfaces, or centers of gravity.

We report here Cotes' method that Settimo uses in his treatise (see fig. 7).

${ }^{3}$ R. Cotes, Harmonia Mensurarum, sive Analysis \& Synthesis per Rationum \& Angulorum Mensuras Promotae: Accedunt alia Opuscula Mathematica: per Rogerum Cotesium. Edidit \& Auxit Robertus Smith, Collegii S. Trinitatis apud Cantabrigienses Socius; Astronomiae \& Experimentalis Philosophiae Post Cotesium Professor, Cantabrigiae, 1722. See also R. Cotes, Logometria, «Philosophical Transactions of the Royal Society of London», vol. 29, $\mathrm{n}^{\circ} 338$, 1714. 
Starting from the circle, let $C A=q$ and $T A=u$ the tangent; therefore $C T=\sqrt{q^{2}+u^{2}}$. Let's put $T t=d u$. Settimo investigates the arc that is the logarithm of imaginary numbers and showed that this solution solves the problem of searching the original integral $\frac{b c m}{a f r} \frac{\frac{1}{2} q^{3} d u}{q^{2}+u^{2}}$.

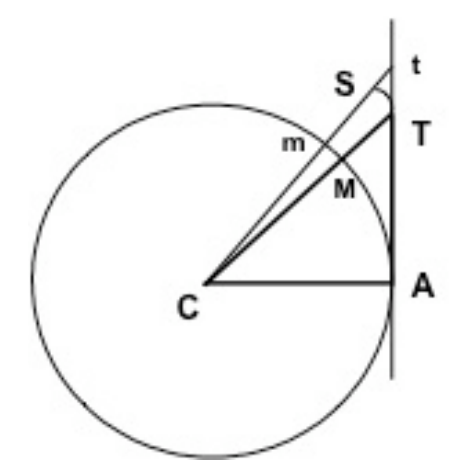

Fig.7. Figure to illustrate Cotes' method

The triangles $S t T$ and $A T C$ are similar, therefore

$$
T t: T S=C T: C A \text { and } T S=\frac{C A \cdot T t}{C T}=\frac{q d u}{\sqrt{q^{2}+u^{2}}} .
$$

$C T S$ and $C M m$ are also similar, therefore

$$
T S: M m=C T: C M \text { and } M m=\frac{T S \cdot C M}{C T}=\frac{q^{2} d u}{q^{2}+u^{2}} .
$$

Since the arc AM represents the integral of $\mathrm{Mm}$, Cotes finds the original integral $\frac{b c m}{a f r} \frac{\frac{1}{2} q^{3} d u}{q^{2}+u^{2}}$. From $A M=\alpha q$ with $\alpha=\arctan \frac{u}{q}$, then

$$
\frac{b c m}{a f r} \frac{1}{2} q \times A M=\frac{b c m}{a f r} \frac{1}{2} q^{2} \arctan \frac{u}{q}
$$


and its derivative is $\frac{b c m}{a f r} \frac{\frac{1}{2} q^{3} d u}{q^{2}+u^{2}}$.

Becoming again to Settimo's treatise, when Settimo supposes the inequality $\frac{s^{2}}{r^{2}}>\frac{a}{b}$, he solves the integral by means of logarithms of imaginary numbers, then (by using Cotes' method) with circular arcs.

Finally, Settimo shows problems on calculus of centre of gravity relative to area and volume of groins.

\section{CONCLUSION}

Various authors have eredited Archimedes, but we know that Prof. Heiberg found the Palimpsest containing Archimedes' method only in 1907 , and therefore it is practically certain that Settimo did not know Archimedes' work.

Archimedes' solutions for calculating the volume of cylindrical wedges can be interpreted as computation of integrals, as Settimo really did, but both methods of Archimedes and Settimo are missing of generality: there is no a general computational algorithm for the calculations of volumes. They base the solution of each problem on a costruction determined by the special geometric features of that particular problem; Settimo however is able to take advantage of prevoious solutions of similar problems.

It is important finally to note that Settimo, who however has studied and knew the modern infinitesimal calculus (he indeed had to consult Roger Cotes and Leonhard Euler with De Martino in order to calculate integrals by using logarithms and circular arcs), considers the construction of the infinitesimal element similarly Archimedes.

Wanting to compare the two methods, we can say that both are based on geometrical constructions, from where they start to calculate infinitesimal element (that Settimo calls "elemento di solidità"): Archimedes" mechanical method was a precursor of that techniques which led to the rapid development of the calculus.

\section{REFERENCES}

1. F. Amodeo, Vita matematica napoletana, Parte prima, Napoli, F. Giannini e Figli, 1905.

2. Brigaglia, P. Nastasi, Due matematici siciliani della prima metà del '700: Girolamo Settimo e Niccolò Cento, «Archivio Storico per la Sicilia Orientale», LXXVII (1981), 2-3, pp. 209276. 
3. R. Cotes, Harmonia Mensurarum, sive Analysis \& Synthesis per Rationum \& Angulorum Mensuras Promotae: Accedunt alia Opuscula Mathematica: per Rogerum Cotesium. Edidit \& Auxit Robertus Smith, Collegii S. Trinitatis apud Cantabrigienses Socius; Astronomiae \& Experimentalis Philosophiae Post Cotesium Professor, Cantabrigiae, 1722

4. R. Cotes, Logometria, «Philosophical Transactions of the Royal Society of London», vol. $29, \mathrm{n}^{\circ} 338,1714$.

5. N. De Martino, Elementa Algebrae pro novis tyronibus tumultuario studio concinnata, auctore Nicolao De Martino in Illustri Lyceo Neapolitano Mathematum Professore, Neapoli, Ex Typographia Felicis Mosca, Expensis Bernardini Gessari, 1725.

6. N. De Martino, Algebrae Geometria promotae elementa conscripta ad usum Faustinae Pignatelli Principis Colubranensis, et Tolvensis ducatus haeredis. Edita vero in gratiam studiosae Juventutis, auctore Nicolao De Martino, Regio Mathematum Professore, Neapoli, Excudebat Felix Mosca Sumptibus Cajetani Eliae, 1737.

7. N. De Martino, Nuovi elementi della geometria pratica composti per uso della Reale Accademia Militare dal Primario Professore della medesima Niccolò Di Martino, Napoli, Presso Giovanni di Simone, 1752.

8. N. De Martino, Elementi della Geometria così piana, come solida, coll'aggiunta di un breve trattato delle Sezioni Coniche composti per uso della Regale Accademia Militare da Niccolò Di Martino Primario Professore della medesima, Napoli, nella Stamperia Simoniana, 1768

9. N. De Martino, Nuovi Elementi della teoria delle mine composti dal fù Niccolò Di Martino Reggio Precettore, e Maestro di Mattematica di Ferdinando IV. Nostro Augustissimo Regnante. Dati alla luce da suo nipote Giuseppe Di Martino Ingeg. Estraordinario, e tenente Aggregato. Dedicati A. S. E. D. Francesco Pignatelli De’ Principi Strongoli Maresciallo di Campo Ajutante Reale, Colonello Governatore del Real Battaglione, e Gentiluomo di Camera, di Entrata coll'Esercizio di S. M., Napoli, Presso Gio. Battista Settembre, 1780, in cui è allegato il Breve trattatino della misura delle volte, composto dal fü Niccolò Di Martino [...].

10. N. De Martino, La «Dissertazione intorno al caso irresoluto dell'equazioni cubiche»: un manoscritto inedito di Niccolò De Martino, a cura di R. Gatto, «Archivio Storico per le Province Napoletane», CVI dell'intera collezione, 1988.

11. L. Euler, Introductio in analysin infinitorum, Lausannae, Apud Marcum-Michaelem Bousquet \& Socios, 1748

12. G. Ferraro - F. Palladino, Il calcolo sublime di Eulero e Lagrange esposto col metodo sintetico nel progetto di Nicolò Fergola, Istituto Italiano per gli Studi Filosofici, Napoli, La Città del Sole, 1995.

13. F. Palladino, Metodi matematici e ordine politico, Napoli, Jovene, 1999.

14. E. Rufini, Il "Metodo" di Archimede e le origini del calcolo infinitesimale nell'antichità, Milano, Feltrinelli, 1961.

15. Figures 1, 2, 3, 4 are from Aspetti didattici della storia del calcolo infinitesimale by M.F. Ingrande. 